\title{
UNDERSTANDING THE IMPACT OF HIGH-RISE BUILDINGS ON ENVIRONMENTAL QUALITY AND SUSTAINABLE URBAN DEVELOPMENT
}

\author{
Fahimeh Abdi \\ Master of Geography and Urban Planning, University of Tabriz, Iran
}

\section{Original Article}

PII: S238315531900003-8

Received: 27 Aug. 2019 Accepted: 21 Nov. 2019 Published: 15 Dec. 2019

Corresponding author:

E-mail: abdi.fahimeh@yahoo.com

\begin{abstract}
Nowadays, increasing population and land prices have made high-rise construction or the vertical growth and development of cities to become inevitable. The benefits of vertical urban growth include preserving arable land to supply and feed the growing population, reducing environmental degradation due to reduced natural land construction, reducing urban traffic and energy consumption, and reducing air pollution resulting from horizontal urban development. The purpose of this paper is to investigate the effects of highrise building on environment quality and sustainable urban development using a descriptiveanalytical research method. The research process has concluded that high-rise buildings can meet the needs of the community based on feasibility studies and design and construction based on appropriate scientific and technical and managerial principles and in accordance with the advanced technologies required for such buildings, such that all the principles and criteria of high-rise building are met.
\end{abstract}

KEYWORDS: High-rise construction, Sustainable development, Sustainability, Environmental quality.

\section{INTRODUCTION}

High-rise construction is a phenomenon that emerged in the world from the late 19th and early 2oth centuries, and the first steps in the constructions of skyscrapers were taken around years 1880 to 1900 in Chicago. With the increasing population worldwide and the growing demand for housing, human beings have tried to meet this need in many ways. Among these practices is the tendency towards towers. This can be considered a fundamental phenomenon in the current urbanization. Today's demands especially population and urbanization growth, have pushed authorities to promote urban growth, to construct high-rise buildings, or, in other words, vertical urban growth. Today, many urban plans are based on increasing the density and construction of high-rise buildings and focusing on mixed-use, as much as possible, to reduce the occupancy level of buildings to optimally utilize urban land, so that a proper relationship can be achieved between 'residential, labor, leisure and travel' functions at the city level and to establish a suitable living environment for today and future generations [1]. The rapid growth of the urban population and consequently the need for housing on one hand and preventing the unnecessary expansion of cities for optimal use of urban land and the resolution of problems, land, space, land use, environmental issues, urban transport, etc. on the other hand, has put forward the "high-rise construction" and the "compact city" model for sustainable urban growth in developed and developing countries. Sustainable Urban Development emphasizes the role of high-leveling in "coordinating the functions of residence, labor, meeting essentials and leisure", as well as optimizing the use of urban land. But as the high-rise development continued in the 70th to 5oth decades, and with the rise of tall towers built in various cities around the world, political reactions took place to control vertical growth. These tensions were mostly due to the problems of high-rise construction that plagued the cities. This issue led to efforts to address the shortcomings and to adopt lawful policies for the high-rise construction process to move towards sustainable urban development [1]. High-rise construction has been able to address many urban issues such as land scarcity, housing scarcity, etc. on one hand, but on the other hand it has caused other problems and irregularities. Western countries have tried to take advantage of high-rise construction and to control the arising issues and problems under applicable laws and regulations. In this regard, our cities are now witnessing the growth and development of high-rise buildings while there is no proper recognition of the importance of the issue and no controlling laws and regulations are available. The year 1950 can be considered as the beginning of the high-rise construction movement in 
Iran. With the outbreak of the Islamic Revolution, high-rise construction was ceased for almost five years. During these years the construction of these types of buildings was limited to the completion of unfinished residential complexes. In recent years, the high-rise construction procedure has grown dramatically in Iran [2]. A thorough and rooted examination of this issue and the problems caused by the incompatibility of this technology with the social conditions of Iranian can be investigated. In particular, due to the variety of issues related to high-rise construction, it is necessary to consider the different technical and social dimensions, despite their positive and constructive interaction, based on sustainable development indicators.

Due to its status as the first metropolis in the country, construction in Tehran has always been a center of attention. In recent years, there has been a significant increase in the construction of higher than 4-storey buildings. The growing trend of population in Tehran, together with the constraint of urban land with increasing housing demand, on one hand, and rising prices of land susceptible to urban development, on the other hand, have led to the development of high-rise construction in recent years in Tehran.

Population density in Tehran as well as its unique building density have led to the selection of this metropolis and analysis of the positive and negative effects of high-rise construction. Considering these cases and other problems facing this metropolis, the need to study and plan for issues such as environmental problems, pollution, housing issues, etc., and provision of appropriate solutions is unavoidable.

\section{Research questions}

1. What are the favorable and unfavorable effects of high-rise construction in terms of environmental quality indicators?

2. What are the social, economic, environmental and physical dimensions of the creation and development of high-rise buildings with regard to sustainable development indicators?

3. What are the factors affecting high-rise construction and its role on urban environment quality?

4. What is the relationship between environmental quality indicators and sustainable development principles in high-rise construction?

\section{Research methodology}

The present research is a qualitative study. The research method is exploratory. This survey is cross- sectional in terms of time criterion and extensive in terms of depth criterion. In this type of research, in order to describe the case study, information is collected from the sample at a certain time period. Also, with regard to the subject under study, this research is an applied study, the results of which will be used immediately to solve problems.

\section{High-rise buildings and urban development theory}

In the second half of the eighteenth century, based on the technical, economic, and social changes brought about by the industrial revolution in Western Europe, these developments led to the emergence of contemporary urbanization in the nineteenth century, as well as the rapid expansion of cities. These fundamental changes and developments were fully consistent with the expansion of the industry [3].

\section{Density}

Population growth is such that $80 \%$ to $90 \%$ of the world's population is expected to urbanize in the early 21st century, and there are two general forms of development to accommodate the explosive population growth in cities:

- Development of existing cities

- Formation of new cities

One of the possible methods to accommodate urban population is to expand the available cities - to eliminate the disturbance and disorder that prevails in large urban communities - and to create a city or metropolitan community that is free from all the disadvantages and shortcomings of existing cities [4].

- Expanding the extended formation of cities (expanding on the horizon)

- Expanding the vertical formation of cities (extension in height).

The necessity to investigate the quality of living environment in high-rise residential complexes

The residential environment in high-rise complexes is not limited to the space inside residential units, but rather includes the spaces between the buildings and the lobbies and the corridors within them, exterior areas of the building and pedestrian access around the complex. The potential adverse consequences of the high density of these complexes makes it necessary to address the issue of quality in these residential environments, which, although not necessarily leading to a deterioration in the quality of life, specific problems 
and complexities which can cause physical and social abnormalities. The aggregate of these anomalies, which manifest in the social dimension in various forms of sedition, sabotage, crime, and in the physical dimension through phenomena such as graffiti and actions such as dumping garbage in corridors, elevators, and lobbies, lead to an inclusive sense of insecurity. The living environment plays an important role in the gradual deterioration and in some cases the eventual demolition of these residential complexes [3].

\section{Relation of high-rise buildings with urban environment}

The design of high-rise buildings should have the least negative impact on the neighborhood. These negative effects include shading, visibility and privacy and the creation of wind tunnels [4]. Therefore, the height and volume of the building should be proportional to the neighborhood. The main nodes and intersections are desirable locations to place high-rise buildings [5].

\section{Perceived quality of residential environment}

A high-quality residential environment induces a sense of well-being and satisfaction for residents through physical, social or symbolic features. Such an environment guarantees the quality of life and a major support for economic, social and cultural activities. The concept of "quality of life" is strongly rooted in health consideration. In the Newman model, health is considered a viable indicator, while in other models the quality of the environment is discussed as a determinant of health. Bloom's model of health is defined as the result of genetic factors, the nature and manner of health conservation, behavior / lifestyle and quality of physical and sociocultural environment.

Residential health and well-being are a vital component of quality of life and social sustainability. Past research has shown the adverse effects of dense population. In the case of developing countries, the effects of high density on health and well-being are far greater and more detrimental than those encountered in crowded settlements, with poorly maintained and inadequate infrastructure [6].

Two broad areas of concern related to respiratory and stressful diseases are those that arise from air pollution in high density areas (due to activity levels and number of vehicles) and mental illnesses which are often associated with overcrowding in high density neighborhoods.
The recent model presented in the area of quality of life is the Ching model which discusses different aspects of "desirable life". The basis of this model is based on four ethical theories: pleasure, dialectical insight, humanism, and formalism. According to the diagram provided by Mitchell, the elements and components of quality of life and their constituent variables include:

- Health: The overall health of any community that is the product of the physical and mental health of individuals and their members.

- Security: An understanding of security is shaped by the safe, secure environment of the individual, the economic security of the individual, and the existence of a regular and orderly life.

- Individual growth: Enjoying the opportunity to entertain, the opportunity to spend leisure time appropriately and the process of education and learning, all make the ideal achievement of individual growth and transformation possible.

- Social Development: The realization of the goal of growth and development in any society depends on factors such as the quality of citizens' political participation, social networks and social interactions, and the structure of the community in question.

Physical environment: In relation to physical environment components, attention to variables such as visual perception and landscape quality, climate, pollution and environmental noise is required [8].

In a culture with high density of life, inadequate size of living spaces affects many aspects of quality of life, which directly affect quality of life and justice, and is limited to choosing better settlement for the deprived people. Inadequate living space or crowded settlement is strongly criticized as having a negative impact on health, social relationship, privacy, and education, so per capita living space is important in assessing the quality of life and sustainability of any neighborhood. Given the relationship between density, amount of living space, and quality of life, it is important to consider the impact of neighborhood density on living space dimensions. High density settlement is often associated with the small size of a housing or garden or outdoor space. Small home size can have negative effects on quality of life. Within a culture of high-density habitation, inadequate size of living space affects many aspects of quality of life, which directly affects justice in society, and is limited to choosing better homes for the deprived. Inadequate living space or settlement density is strongly criticized as having a negative impact on 
health, social relationships, privacy, and education [9], therefore, per capita is important in assessing quality of life, home satisfaction, and sustainability of any neighborhood. Considering the relationship between density, amount of living space, and quality of life, the impact of neighborhood density on living space dimension should be investigated.

\section{Analysis of questions}

1. What are the favorable and unfavorable effects of high-rise construction in terms of environmental quality indicators?

Today, high-rise buildings are the phenomena faced by that the world, especially large cities. Highrise construction causes new problems for land use due to its negative environmental impacts, including increased population density, environmental pollution, reduced access to fresh air and sunlight. But due to population growth and land scarcity, high-rise construction cannot be avoided. Therefore, for high-rise construction, consideration must be given to geographical location factors, technical regulations, immunization, green space, wind direction, distance to other buildings, design in terms of visibility and city appearance [10]. This study shows that due to changes in wind and wind direction and also the density of high-rise buildings as a source of pollution, air pollution is increased in large metropolitan areas. Therefore, to reduce the negative impacts of high-rise construction on environmental pollution, fans should be considered in the design of high-rise buildings. Unfortunately, the failure of the construction in environmental protection and the lack of control over the rules in the construction process causes environmental pollution, especially air pollution. Re-evaluating the rules, along with tighter controls, can improve the quality of air in large cities with the use of green space on the ground and on the roofs of buildings [11]. This study shows that the average concentration of carbon gas rises from the lowest levels of the building to the $2^{\text {nd }}$ to $3^{\text {rd }}$ floors, but gradually decreases in the upper floors through an irregular process. This is probably due to the higher wind speeds in the upper part of the building. Higher wind speeds reduce pollution severity. Although increasing altitude increases the distance from major sources of pollution (cars), the volume of pollution is not related to the distance from sources of pollution. Rather, it depends on factors such as local winds and the turbulent flow around the building, which causes pollution to accumulate in one part of the building and disperse to the other part of the building. Highrise buildings have special effects on the climate and play an important role in the environment. Most of the changes that high-rise buildings cause to the environment are related to wind and sunlight. Adjacent complex buildings are limited by sunlight as they shade the lower floors of tall buildings as well as short buildings.

2. What are the social, economic, environmental and physical dimensions of the creation and development of high-rise buildings with regard to sustainable development indicators?

Until now, various researchers have criticized the abnormal and negative social, cultural and psychological effects of high-rise buildings. Since social, cultural and psychological impacts of living and working in high-rise residential complexes are of great importance, and social interactions and psychological impacts are much wider, this has led to criticism of high-rise construction in residential buildings. In fact, the study of residential buildings is important because housing has an important place in socio-cultural and psychological categories, such that housing is the most important provider of civilization and home is the best preserver of social culture. Housing is one of the key factors in the balance and sustainability of the human community and protects the family and relationship between its members. That is why adequate housing, like other human needs, is a basic human right. Lack of attention to the role of housing in urban family social relations, without any doubt, makes it impossible to enjoy high social behaviors and high human values [12]. In the past, all residents of a neighborhood in Iran were interested in the surrounding issues and there was some degree of coherence and relative social control. While the social, cultural, economic and political developments of society in recent decades have been replaced with some kind of indifference, lack of housing and inadequate quality and lack of attention to its role in social relationships are associated with increased rates of delinquency, divorce and social breakdown. Therefore, paying attention to the importance and role of housing from social dimensions is effective in the cultural and psychological development of society [14]. This is especially important when living at high altitudes causes a change in the human environment, followed by a change in living culture. Therefore, the construction of high-rise buildings, regardless of the cultural issues of the community, cannot be a suitable solution to the housing problem. Although residential areas have witnessed the introduction and expansion of foreign and mostly western patterns and methods over the past century, it seems necessary to recognize the 
problems created and find solutions to co-ordinate high-rise buildings specific to Iranian society in order to improve and promote living conditions [14]. Therefore, to understand the social, cultural and psychological aspects of high-rise buildings, the impacts of these buildings on residents should be examined in the following areas to determine the amount of increase in density and capacity of highrise construction in residential areas:

Residential high-rise construction and neighborhood relations

Residential high-rise construction and family commuting

Residential high-rise construction, ethical and educational issues

Residential high-rise construction \& Mental Issues

Residential high-rise construction \& Security

Residential high-rise construction and social classes and groups

Residential high-rise construction and property

Residential high-rise construction \& Partnership

Residential high-rise construction and indigenous identity [15]

In general, what follows is that apartment life is not suitable for all social groups and classes. Of course, the issue needs to be scrutinized more carefully, but overall, it can be concluded that highrise living is more suitable for middle-class people than poor urban strata who often have a rural culture. Also, in a high-rise building, due to very close proximity, if residents have also a similar culture, better relationships and greater resident satisfaction will be formed.

3. What are the factors affecting high-rise construction and its role on urban environment quality?

Irregular development at the urban level is one of the dangers that always threaten the sustainability of the environment and consequently the sustainability of buildings. The low population density of a city that is generally inconsistent with the requirements of a sustainable city is usually formed in the suburbs and has been challenged and criticized by social and environmental sustainability experts [16]. High-rise construction can be considered as an approach to prevent this problem. In other words, the pattern of the city leads to functionalism by high-rise construction, and the optimal use of land becomes feasible from this perspective. Beyond social benefits, the dense urban pattern can also have important environmental benefits. Concentrated cities can be designed through a coherent and integrated planning to optimize energy consumption and reduce resource consumption as well as reduce environmental pollution and prevent reaching rural areas around cities [17]. Some of the undesirable consequences of large and low-density cities in terms of sustainability can be described as follows:

$\square$ Consumption of large amounts of high-quality agricultural land for housing and roads;

Increase of constructed lands resulting in increased surface water flow, gasoline consumption and other wastes;

$\square$ Increase of energy consumption and pollution by reducing the use of public transport, pedestrianism and cycling;

$\square$ Increase of energy consumption in open and single-family residential units through their lower design efficiency than compact housing forms

4. What is the relationship between environmental quality indicators and sustainable development principles in high-rise construction?

In sustainable urban development, the quality of human life is centered on urban space, so that the continuity of citizens' lives is enhanced by social prosperity and does not harm the sustainability of the urban environment. Attention to communication is the strength of sustainable development theory which can lead to sustained development [18].

There are many physical factors involved in moving to a sustainable city. However, mere physical changes without the backing of economic and ecological developments will not sustain cities. For a closer look, in this study, the impacts of building density factor on the level of human needs and environmental quality in high-rise buildings were specifically investigated. Since building density does not necessarily affect all aspects of human needs and all aspects of urban quality of life, only the indicators of urban quality of life where emphasized that vary with urban density variations in general and building congestion in particular.

\section{CONCLUSION}

The need for a high-rise construction strategy is increasingly apparent, given the growing population and land constraints in the present. High-rise buildings, being the product of technological advancement, can cause various environmental contaminations and abnormalities, including visual disturbances, if they are not adequately controlled and monitored, due to adverse environmental impacts associated with high population and building densities. Issues such as increased rentals 
in the area, lack of coordination and balance between available density and infrastructure capacity, inadequate ride and pedestrian access, inadequate transportation, traffic, lack of urban parking and noise pollution and visual effects complications due to unmanageable density and overcrowding of high rise buildings, especially in residential areas, can play a role as specific environmental signs and characteristics in conflict with the real needs of the people in their value hierarchy, resulting in a sense of inability to control the living space and therefore lack of a comfortable, relaxed and satisfying experience in urban life. It can be stated that high-rise buildings can meet the needs of the community when they are built based on feasibility studies and scientific, technical, and management design, and in accordance with the advanced technologies required for such buildings, such that all the high-rise construction criteria and principles are met.

\section{Competing interests}

The author declares that they have no competing interests.

\section{REFERENCES}

[1] Hasanpour loumer, S (2014). The Typology of Traditional Houses in Talesh City: Case Study of Khalehsara 57 Village. JHRE. 33 (147): 117-131. Google Scholar

[2] Hasanpour loumer, S. Toofan, S (2019). Visual and Structural Features of Sash Windows in Masouleh Historical City. Islamic Art Studies, 15(34): 72-92. Google Scholar

[3] Bemanyan, M (2011). City and Tall Building, Tehran: Nashr Shahr Publishing Institute.

[4] Azizi, M. M. Motavasseli, M (2012). Evaluation of Types of High-Rise Residential Buildings in terms of Impact on Urban Landscape; Urban Management, 30: 112-91.

[5] Mokhtabad, M. Mohammadi Zadeh, S (2009). A Survey on Urban Semiotics and Its Role in the Readability of Urban Spaces (Case Study: Shahr Esfahan), Iranian Social Development Studies. 1(4): 31-69. Google Scholar

[6] Wood A. (2010). Tall Buildings: Search for a New Typology, Thesis submitted to the University of Nottingham for the Doctor of Philosophy degree, July 2010. Google Scholar
[7] Sharifi A, Murayama A. (2013). Changes in the traditional urban form and the social sustainability of contemporary cities: A case study of Iranian cities. Habitat International. 38:126-34. Google Scholar ; https://doi.org/10.1016/j.habitatint.2012.05.007

[8] Razaghi Asl, S. M. Mahdavi Nia, M. Feizi M. Daneshpour, AS (2010). Vertical Urban Design, Concepts and Implementation Requirements in Tehran, Nazar Bagh, 13: 13-16. Article link ; Google $\underline{\text { Scholar }}$

[9] Arkinet (June 2010) Another Chinese town bites the dust, September, Design Build Network, Pujiang New Town, Shanghai, China, accessed on 14 September 2010.

[10] Hesam, M., Pour Ahmad, A (2013). Environmental Impacts of Horizontal Urban Development (Case Study: Gorgan), Journal of Environmental Studies, 3: 91-104. Google Scholar ; https://dx.doi.org/10.22059/jes.2013.35892

[11] Haghighi Boroujeni, S (2011). Imposing Architecture on Sustainable Development Path, Abadi Journal, 68: $20-26$

[12] Gifford, R (2007). The Consequences of Living in High-Rise Buildings. Architectural Science Review, 50(1): 2-17. Google Scholar ; https://doi.org/10.3763/asre.2007.5002

[13] Jacobs, J, (2007), The Death and Life of Major American Cities Translated by: Hamid Reza Parsi and Arezou Aflatuni, First Edition, Tehran, Tehran University Press and Publishing Institute. Google $\underline{\text { Scholar }}$

[14] Ghaem Maghami, P. Zarghami, A. Pourdiehimi, S (2010). Principles of Social Sustainability in Residential Complexes, Safeh Journal, 51: 75-87. Google Scholar https://www.sid.ir/en/journal/ViewPaper.aspx?ID= $\underline{211144}$

[15] Colantonio A, Dixon T, Ganser R, Carpenter J, Ngombe A. Measuring Socially Sustainable Urban Regeneration in Europe. Oxford Institute for Sustainable Development (OISD). Google Scholar

[16] Ali, M. M., \& Al-Kodmany, K (2012). Tall Buildings and Urban Habitat of the 21st Century: A Global Perspective. Buildings, 2(4): 384-423. Google Scholar https://doi.org/10.3390/buildings2040384

[17] Kamran, F. Hosseini, A. Zabihinia, Kh (2009). A Study of the Socio-Cultural Problems of Apartment Life in New Pardis City, Journal of Social Research, 25: 21-40.

[18] Balilan, L., Hasanpour Lomer, S (2019). Geometric patterns and Golden proportion common language of architecture and art in the Abyaneh village, 7(9): 45-68. Google Scholar 